\title{
Decontamination of naturally contaminated liquid nitrogen storage tanks
}

\author{
Gilson Antonio Pessoa', Mara lolanda Batistella Rubin², Carlos Antonio Mondino Silva², \\ Denize Costa da Rosa ${ }^{3}$
}

\footnotetext{
${ }^{1}$ Doutorando do Programa de Pós-Graduação em Medicina Animal-Equinos, Universidade Federal do Rio Grande do Sul, Porto Alegre - RS, Brasil.

${ }^{2}$ Departamento de Clínica de Grandes Animais, Universidade Federal de Santa Maria, Santa Maria - RS, Brasil.

${ }^{3}$ Faculdade de Medicina Veterinária, Universidade de ljuí, Ijuí - RS, Brasil.
}

\begin{abstract}
The objective of this study was to evaluate the efficacy of cleaning and decontamination procedures in liquid nitrogen tanks. We evaluated 151 canisters and 133 bottoms from 133 nitrogen tanks of companies or farms for the presence of bacteria and fungi. Samples were collected from the canisters and the bottom of tanks containing liquid nitrogen. Tanks were divided into Group 1 (G1): tanks decontaminated with $2 \%$ glutaraldehyde - Glutaron ${ }^{\circledR}$ II ( $\mathrm{n}=16$ canisters in 8 tanks); Group 2 (G2): decontamination with 70\% ethanol ( $\mathrm{n}=20$ canisters in 10 tanks); and Group 3 (G3): decontamination with $70 \%$ ethanol ( $\mathrm{n}=115$ canisters in 115 tanks). Tanks in Groups 1 and 2 belonged to companies; Group 3 tanks belonged to farms. The culture of canisters showed twelve genera of bacteria and five genera of fungi. Bacillus cereus was the most prevalent bacterial contaminant (42/133) in liquid nitrogen tanks (31.57\%). Decontamination by $2 \%$ glutaraldehyde plus $70 \%$ ethanol was effective and no difference was found between the decontamination methods of Groups 1 and 2 . In Group 3 the decontamination method was considered effective. Handling procedures with high hygienic standards should be recommended to avoid contamination of liquid nitrogen tanks on farms.
\end{abstract}

Key Words: artificial insemination, bacteria, fungi, semen

\section{Introduction}

Liquid nitrogen usually exhibits a very low microbial count during production, but during its storage and distribution it may become an effective media for the cryopreservation of fungal spores, yeasts, bacteria, and viruses (Grout and Morris, 2009). It is known that contamination can occur during tissue, semen or embryo storage in liquid nitrogen and the cryopreservation of external microorganisms can occur by extravasation of cryoprotectors used in semen from damaged straws (Piaseka-Serafin, 1972; Bielansky et al., 2003; Bielanski, 2005a; Morris, 2005). As water vaporizes, cools and freezes above an open liquid-nitrogen tank, small ice crystals with a high electrostatic charge are formed and capture airborne microorganisms which fall into the tank (Grout and Morris, 2009).

According to Bielanski et al. (2003), the prevention of microbial contamination and disease transmission during the storage and/or transport of cryopreserved superior genetic material is recommended to avoid the direct exposure of

Received June 5, 2013 and accepted February 21, 2014

Corresponding author: gilsonpessoavet@yahoo.com.br

http://dx.doi.org/10.1590/S1516-35982014000500004

Copyright @ 2014 Sociedade Brasileira de Zootecnia. This is an Open Access article distributed under the terms of the Creative Commons Attribution Non-Commercial License, which permits unrestricted non-commercial use, distribution, and reproduction in any medium, provided the original work is properly cited. the genetic materials to liquid nitrogen. Transmission of infection through the semen used in artificial insemination may occur because of environmental factors during semen storage in liquid-nitrogen storage tanks or due to low straw quality or environmental contaminants during the breaking and emptying of contaminated straws.

This study aimed to isolate and characterize bacteria and fungi that contaminate canisters of liquid nitrogen and bottoms of tanks used to store semen and embryos on farms in Rio Grande do Sul, Brazil. Moreover, the efficacy of cleaning and decontamination procedures was evaluated by collecting samples before and after decontamination of the tanks. These samples were used to identify bacteria and fungi contaminants.

\section{Material and Methods}

This study was performed using 133 non-hydrophilic liquid-nitrogen tanks from 93 companies and farms located in Southern Brazil in Rio Grande do Sul (latitude $27^{\circ} 30^{\prime} \mathrm{S}$ to $31^{\circ} \mathrm{S}$ and longitude $51^{\circ} 30^{\prime} \mathrm{W}$ to $55^{\circ} 30^{\prime} \mathrm{W}$ ). Swab samples were collected before tank decontamination. All personnel involved washed and disinfected their hands, and the bottlenecks of the tanks were cleaned. From each of 133 semen storage tanks used in the study, technicians collected swabs from two canisters still immersed in liquid nitrogen, 
and one swab from the bottom of the tank. Samples were conditioned in Stuart transport media, packed into a Styrofoam box with ice packs and sent within two hours to the laboratory for culture and identification of bacterial and fungal agents.

The first part of the study was conducted with 18 tanks used for the storage of semen at companies (Groups 1 and 2 ). The tanks were emptied of liquid nitrogen and allowed to reach room temperature to hold the wash solution. Canisters $(\mathrm{n}=16)$ and tanks $(\mathrm{n}=8)$ from Group 1 (G1) were washed with neutral soap (Extran ${ }^{\circledR}$; ref. 107553; Merck KGaA. 64293 Darmstadt, Germany), flushed with water, immediately disinfected by filling with $2 \%$ glutaraldehyde (Glutaron II $^{\circledR}$ - Indústria Farmaceutica Rio Química Ltda. 15.057-430 São José do Rio Preto. São Paulo, SP. Brazil) and allowed to sit for 3 hours. The tanks were then flushed three times with sterile water and left to dry at room temperature before collecting swab samples to be tested for contaminants. The canisters were dried in an oven at $60{ }^{\circ} \mathrm{C}$, and the tanks were emptied and left to dry at room temperature in the inverted position on disinfected benches with sterile gauze protecting the necks. Postdecontamination samples were collected for bacteriological and fungal evaluations from two of the canisters and the bottom of each tank following the same method previously described for the pre-decontamination samples. When this test was negative for bacteria and fungi, the tank was again filled with liquid nitrogen to full capacity.

Tanks of Group $2(\mathrm{G} 2 ; \mathrm{n}=10)$ and their canisters $(\mathrm{n}=20)$ belonged to companies and had their samples for culture collected before and after decontamination, washing and drying according to the procedure performed in Group 1. In order to disinfect the tanks, they were filled with $70 \%$ ethanol and allowed to sit for 3 hours.

The second part of this study was conducted with 115 tanks used for the storage of semen on farms (Group $3=\mathrm{G} 3$ ). Samples from all the tanks were collected for bacterial culture using the same procedure as described previously except that only a single sample from each canister and the bottom of a tank was collected. Next, the tanks were emptied and subjected to the same decontamination process performed for Group 2. At the moment of emptying, in the G3 tanks $(n=18)$ that contained much sediment, sediment samples were collected aseptically for microbiological culture. This group was tested in order to evaluate if this procedure could be a viable methodology to be adopted for decontamination on farms. Most of these tanks (G3) were stored without external protection (cover or box).

Differentiation and identification of gram-positive or gram-negative cocci or bacilli was performed as described by Koneman et al. (2001). Fungi and yeasts were identified according to Neufeld (1999) and Barnett et al. (2000).

The design of the study was through random samples for Groups 1 and 2. The analysis was based on quantitative nonpaired samples with non-normal distribution. For statistical analysis a 5\% level of significance was used. In Group 3, the efficacy of decontamination method was measured by McNemar's test with a 95\% confidence interval.

\section{Results}

The liquid-nitrogen storage tanks contained broken straws and sediments such as organic material, oxidized wire and nails, clothes pins, pen lights, plastic and cotton or synthetic fibers (Figure 1). Bacillus cereus was the main contaminant isolated pre-decontamination in the tanks from Groups 1, 2 and 3 (Tables 1, 2 and 4). The samples collected after washing and decontamination with $2 \%$ glutaraldehyde showed no bacterial contamination in the bottom of tanks, but in tank number five Mucor spp. was not eliminated from the canisters.

After decontamination of the Group 2 tanks (Table 2), Bacillus cereus, Mucor spp., Cladosporium cladosporioides, and Escherichia coli were isolated from six canisters of tanks number 2, 5 and 10. Two canisters from tank number five had fungal contamination. Additionally, Mucor spp. remained in the bottom of tank number five (Table 2).

In comparing the canisters and the bottom surfaces of the tanks no difference was shown $(\mathrm{P}=0.3269)$ between the decontamination methods used for tanks of Groups 1 and 2. Both methods were able to decontaminate the canisters and bottom of containers.

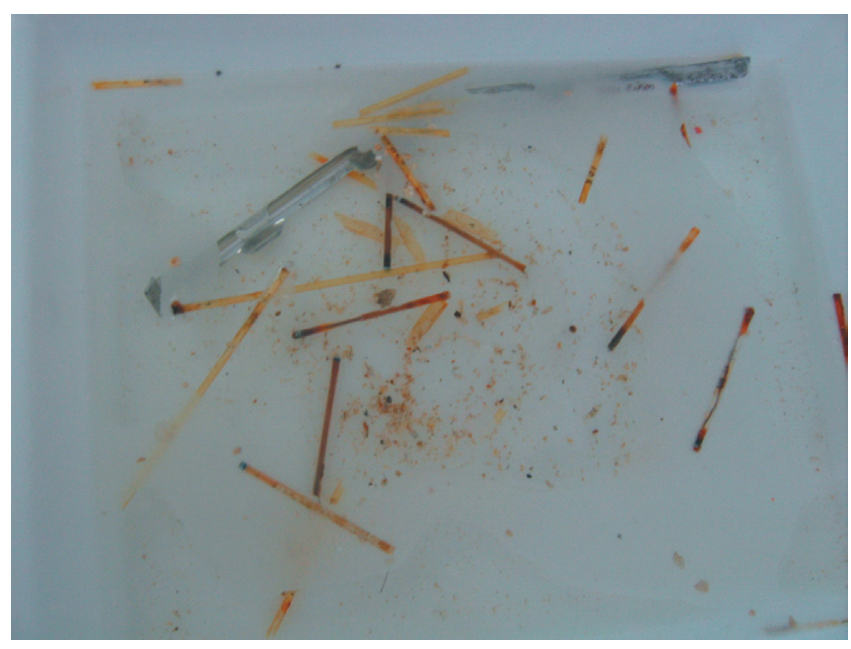

Figure 1 - Material found at the bottom of Group 3 tank number five (farm tank) after emptying. 
In Group 3, a high percentage (84.35\%; 97/115) of tanks was contaminated by bacteria, fungi, or both (Table 3) in the samples collected prior to cleaning and decontamination processes. Bacterial agents were found in $84.3 \%(97 / 115)$ and fungi were found in $69.5 \%(80 / 115)$ of the tanks (Table 4). Bacillus cereus was the most common agent isolated at the bottom of 30 tanks $(26.0 \%, 30 / 115)$ (Table 4). After decontamination, only $9.6 \%(11 / 115)$ of

Table 1 - Bacteria and fungi detected in tanks $(n=8)$ with liquid nitrogen (Group 1) before and after decontamination with $2 \%$ glutaraldehyde

\begin{tabular}{lccccc}
\hline \multirow{2}{*}{ Tank } & \multicolumn{2}{c}{ Culture pre-decontamination } & & \multicolumn{2}{c}{ Culture post-decontamination } \\
\cline { 2 - 3 } \cline { 5 - 6 } & Canisters & Bottom & & Canisters & Bottom \\
\hline 1 & A, Bc, E & A, Bc & & $(-)$ & $(-)$ \\
2 & A, Bc & A, Bc & & $(-)$ & $(-)$ \\
3 & E, Sh & E, Sh, Bc & & $(-)$ & $(-)$ \\
4 & Sh, Bc & Bc & & $(-)$ & $(-)$ \\
5 & M, Sh & M, Sh, Bc & & M (++) & $(-)$ \\
6 & A, Bc & A, Bc & & $(-)$ & $(-)$ \\
7 & St & St, Bc & & $(-)$ & $(-)$ \\
8 & M, Bc & M, Bc & $(-)$ & $(-)$ \\
\hline
\end{tabular}

A - Acinetobacter spp; Bc - Bacillus cereus; E - Escherichia coli; M - Mucor spp.; Sh - Staphylococcus haemolyticus; St - Streptococcus spp.

Canisters - culture performed from two canisters of each tank; $(+)$ - positive culture; (-) - negative culture.

Table 2 - Bacteria and fungi detected in tanks $(\mathrm{n}=10)$ with liquid nitrogen (Group 2) before and after decontamination with $70 \%$ ethanol

\begin{tabular}{lccccc}
\hline \multirow{2}{*}{ Tank } & \multicolumn{2}{c}{ Culture pre-decontamination } & & \multicolumn{2}{c}{ Culture post-decontamination } \\
\cline { 2 - 3 } \cline { 5 - 6 } & Canisters & Bottom & & Canisters & Bottom \\
\hline 1 & Bc, E & Bc, E & & $(-)$ & $(-)$ \\
2 & Bc, C, E & Bc, C, E & & C (++) & $(-)$ \\
3 & C, Sa, P & Sa, C, P & & $(-)$ & $(-)$ \\
4 & Bc, C, E & Bc, Cy & & $(-)$ & $(-)$ \\
5 & M, E & M, E & & M, E (++) & M (+) \\
6 & Bc, P & Bc, P & & $(-)$ & $(-)$ \\
7 & Bc, Ps & Bc, Ps & & $(-)$ & $(-)$ \\
8 & En, M & En, M & & $(-)$ & $(-)$ \\
9 & Cy, Ps & Cy, Ps & & $(-)$ & $(-)$ \\
10 & Bc, E & Bc, E & & B, E (++) & $(-)$ \\
\hline
\end{tabular}

$\mathrm{Bc}$ - Bacillus cereus; $\mathrm{C}$ - Cladosporium cladosporioides; $\mathrm{Cy}$ - Corynebacterium spp.; E - Escherichia coli; En - Enterobacter spp.; M - Mucor spp.; P - Proteus mirabilis; Ps - Pseudomonas aeruginosa; Sa - Staphylococcus aureus.

Canisters - culture from two canisters of each tank; $(+)$ - positive culture; $(-)$ - negative culture. cultures from tanks and canisters revealed the presence of bacteria and/or fungi. The method was considered effective $(\mathrm{P}=0.001)$ using McNemar's test with odds of 0.209 (CI: 0.118 to 0.351$)$.

\section{Discussion}

Two potential sources of contamination in tanks used for cell cryopreservation are the stored material and the liquid nitrogen itself. During storage over a long period of time, ice sediment may accumulate inside the tank. This sediment can be a source of contamination for cryopreserved biological tissues (Morris, 2005). Thibier and Guerin (2000) described that such contaminants can be present in extenders, on equipment, and in the liquid nitrogen as well. In this study, large amounts of sediment were found in eighteen Group 3 tanks (farm tanks). The sediment showed the same bacterial flora found in swabs from canisters and bottoms.

Bielanski and Stewart (1996) showed that embryonic development is affected by bacteria such as Corynebacterium spp., Streptococcus spp., Staphylococcus spp., Micrococcus spp., and Pseudomonas spp. when present in the culture media for in vitro bovine embryo production. These findings are important because semen and embryos are often kept together in liquid-nitrogen tanks. As reported by Bielanski et al. (2000) many viral and bacterial agents survive cryoprotective storage and can be transmitted through liquid nitrogen to sperm cells, embryos and stored tissues. This risk could be estimated by identifying agents isolated in liquid-nitrogen tanks and canisters (Russel et al., 1995).

Papis (2001) reported that contaminated liquid nitrogen used in the cryopreservation of embryos in open systems (Open Pulled Straws) presents a high risk of bacterial or viral contamination for the cryopreserved cells. Semen and embryos may be contaminated with potentially pathogenic agents, which can contaminate liquid nitrogen when stored in open or defective storage dewars (Bielanski, 1997).

Table 3 - Distribution of positive and negative cultures in canisters and bottoms of liquid nitrogen tanks before and after decontamination with $2 \%$ glutaraldehyde or $70 \%$ ethanol

\begin{tabular}{|c|c|c|c|c|c|c|c|c|c|c|c|c|c|}
\hline \multirow{3}{*}{$\begin{array}{l}\text { Tank } \\
\text { Group: } \\
\text { Procedure (n) }\end{array}$} & \multicolumn{6}{|c|}{ Pre-decontamination } & \multicolumn{6}{|c|}{ Post-decontamination } & \multirow{3}{*}{ P-value } \\
\hline & \multicolumn{3}{|c|}{ Canister } & \multicolumn{3}{|c|}{ Bottom } & \multicolumn{3}{|c|}{ Canister } & \multicolumn{3}{|c|}{ Bottom } & \\
\hline & $\begin{array}{c}\text { Positive } \\
\text { n (\%) }\end{array}$ & $\begin{array}{c}\text { Negative } \\
\mathrm{n}(\%)\end{array}$ & $\mathrm{n}$ & $\begin{array}{c}\text { Positive } \\
\text { n (\%) }\end{array}$ & $\begin{array}{c}\text { Negative } \\
\mathrm{n}(\%)\end{array}$ & $\mathrm{n}$ & $\begin{array}{c}\text { Positive } \\
\mathrm{n}(\%)\end{array}$ & $\begin{array}{c}\text { Negative } \\
\mathrm{n}(\%)\end{array}$ & $\mathrm{n}$ & $\begin{array}{c}\text { Positive } \\
\text { n (\%) }\end{array}$ & $\begin{array}{c}\text { Negative } \\
\mathrm{n}(\%)\end{array}$ & $\mathrm{n}$ & \\
\hline G1: Glutaraldehyde (8) & $16(100)$ & $0(0)$ & 16 & $8(100)$ & $0(0)$ & 8 & $2(12.5)$ & $14(87.5)$ & 16 & $0(0)$ & $8(100)$ & 8 & $<0.0001$ \\
\hline G2: Ethanol (10) & $20(100)$ & $0(0)$ & 20 & $10(100)$ & $0(0)$ & 10 & $6(30)$ & $14(70)$ & 20 & $1(10)$ & $9(90)$ & 10 & 0.0001 \\
\hline G3: Ethanol (115) & $97(84.3)$ & $18(15.7)$ & 115 & $97(84.3)$ & $18(15.7)$ & 115 & $11(9.6)$ & $104(90.4)$ & 115 & $11(3.5)$ & $104(96.5)$ & 115 & $<0.0001$ \\
\hline
\end{tabular}


Semen contamination has been detrimental during in vitro fertilization procedures as well as in artificial insemination (Kim et al., 1998). Zhu et al. (2004) investigated contamination sources and incidences of microorganism contamination during in vitro fertilization and transfer of embryos in humans. Escherichia coli and fungi were the most common microorganisms found. Therefore, frozenthawed semen was considered to be a potential source of contamination for the in vitro culture systems. This statement was corroborated by D'Angelo et al. (2006),

Table 4 - Bacteria and fungi detected in canisters, bottoms and sediments of 115 tanks (Group 3) with liquid nitrogen before and after decontamination with $70 \%$ ethanol

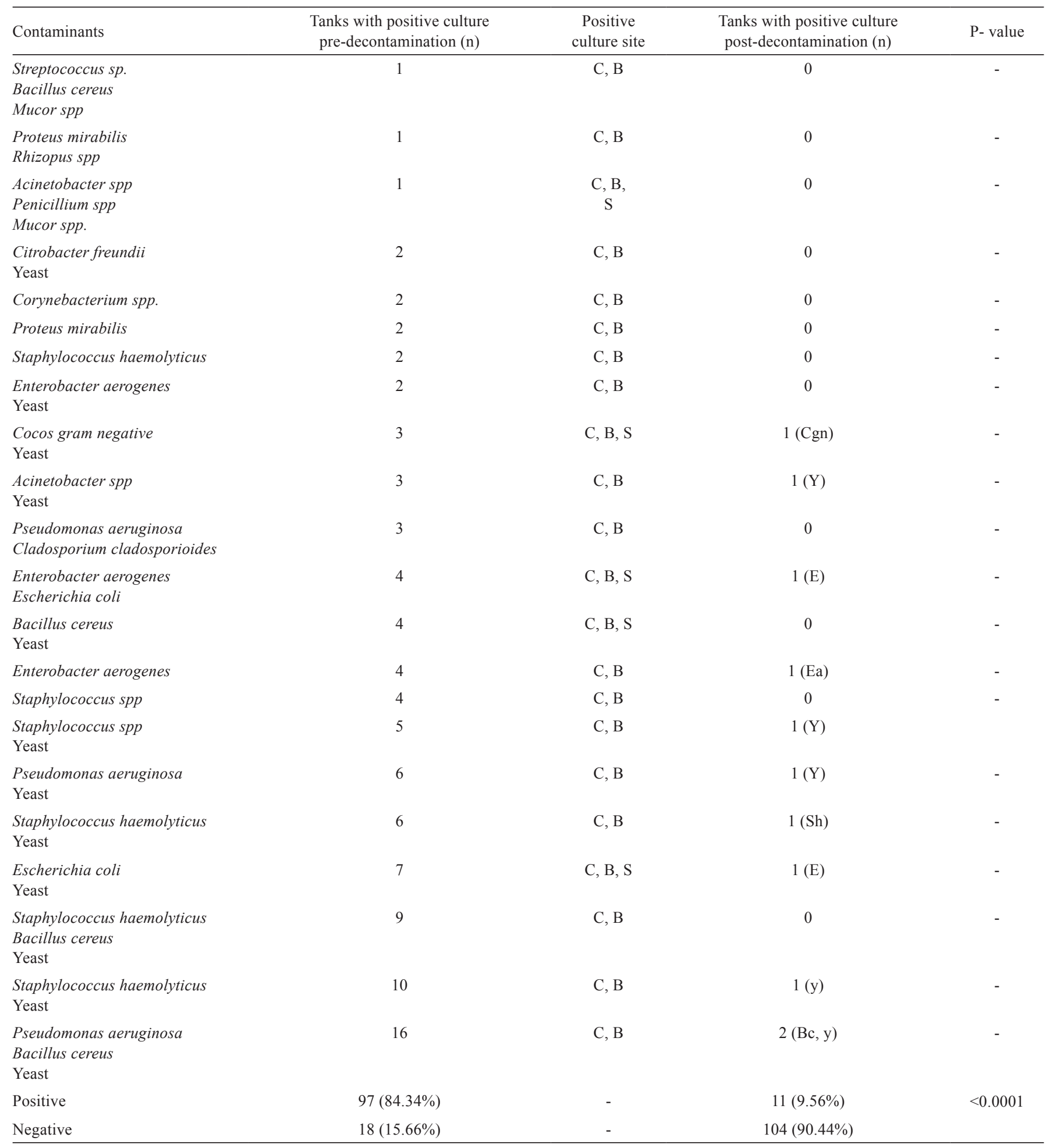

C - canisters; B - bottom; S - sediment; Cgn - Coccus gram negative; Y- yeast; E - Escherichia coli; Ea - Enterobacter aerogenes; Sh - Staphylococcus haemolyticus; Bc - Bacillus cereus. 
showing that the presence of bacteria in semen at the in vitro fertilization procedure is unacceptable, even at low concentrations. Therefore, contaminated semen storage tanks represent a great risk for in vitro embryo production programs.

Fountain et al. (1997) conducted a survey of fungal and bacterial contamination of liquid-nitrogen freezers used to store hematopoietic stem cells, and of 583 cultures tested, $1.2 \%$ were found to be contaminated by microorganisms. Five freezers were heavily contaminated with Aspergillus spp. The microbial contamination found in the freezers was similar to the microbes found in the contaminated cultures.

Alcohols exhibit rapid broad-spectrum antimicrobial activity against vegetative bacteria (including mycobacteria) but are not sporicidal (McDonnel and Russel, 1999). Therefore, these products only inhibit sporulation and spore germination, but this effect is reversible. Glutaraldehyde has a broad spectrum of activity against bacteria and their spores, fungi, and viruses, and a considerable amount of information is now available about the ways whereby these organisms are inactivated. These bactericidal studies demonstrated a strong binding of glutaraldehyde to outer layers of organisms such as E. coli and Staphylococcus aureus (McDonnel and Russel, 1999).

Bielanski (2005b) verified the absence of bacteria or viruses in samples of semen and embryos stored in hydrophobic containers (tanks) after their disinfection with biocides such as sodium hypochlorite, paracetic acid, ethanol, formalin or sterilization by ethylene oxide. Application of gas sterilization using ethylene oxide to both types of dry shippers was fully effective as a means of disinfection. The advantages of using ethylene dioxide are its broad spectrum of antimicrobial activity as well as the elimination of the introduction of liquid solutions into the dry shipper chamber, which lowers the potential for damage of the liquid-nitrogen absorbent (Bielanski, 2005b).

Ethylene oxide is the product recommended for sterilization of liquid-nitrogen tanks. However, ethylene oxide is difficult to access at the farm level in many countries as in Brazil. For this reason the method was not included in our study. The decontamination of storage tanks with $70 \%$ ethanol is an effective and easily accessible procedure for farms.

Farmers, artificial insemination practitioners and veterinarians should also ensure that tanks are kept in a clean and protected place, particularly on cattle farms where tanks have shown high contamination levels.

\section{Conclusions}

Liquid-nitrogen tanks at up to $84.3 \%$ of farms and $100.0 \%$ of companies are contaminated with bacteria, fungi or both. Decontamination of liquid-nitrogen tanks and canisters will be beneficial as a method of sanitation in the storage of gametes and embryos on farms.

\section{Acknowledgments}

The authors are grateful to commercial semen distributors and farmers for allowing the use of nitrogen tanks. This study was supported by grant from FAPERGS/RS, Brazil. Project Proade 3, Proc. 05/23100.

\section{References}

Barnett, J. A.; Payne, R. W. and Yarrow, D. 2000. Yeast, characteristics and identification. 3rd ed. Cambridge University, Cambridge.

Bielanski, A. and Stewart, B. 1996. Unbiquos microbes isolated from in vitro fertilization (IVF) system. Theriogenology 45:269(abstr.).

Bielanski, A. 1997. A review on disease transmission studies in relationship to production of embryos by in vitro fertilization and to related new reproductive technologies. Biotechnology Advances 15:633-656.

Bielanski, A.; Nadin-Davis, S.; Sapp, T. and Lutze-Wallace, C. 2000. Viral contamination of embryos cryopreserved in liquid nitrogen. Cryobiology 40:110-116.

Bielanski, A.; Bergeron, H.; Lau, P. C. K. and Devenish, J. 2003. Microbial contamination of embryos and semen during long term banking in liquid nitrogen. Cryobiology 46:146-152.

Bielanski, A. 2005a. Non-transmission of bacterial and viral microbes to embryos and semen storage in the vapour phase of liquid nitrogen in dry shippers. Cryobiology 50:206-210.

Bielanski, A. 2005b. Experimental microbial contamination and disinfection of dry (vapour) shipper dewars designed for shortterm storage and transportation of cryopreserved germplasm and other biological specimens. Theriogenology 63:1946-1957.

D’Angelo, M.; Pavão, D. L.; Melo, G. M.; Rojas, N.; Souza, R. J.; Athayde, C.; Galuppo, A. G. and Pinheiro, E. S. 2006. Acceptable microorganisms concentration in a semen sample for in vitro embryo production. Brazilian Journal of Microbiology 37:571-572.

Fountain, D.; Ralston, M.; Higgins, N.; Gorlin, J. B.; Uhl, L.; Wheeler, C.; Antin, J. H.; Churchill, W. H. and Benjamin, R. J. 1997. Liquid nitrogen freezers: A potential source of microbial contamination of hematopoietic stem cell components. Transfusion 37:585-591.

Grout, B. W. W. and Morris, G. J. 2009. Contaminated liquid nitrogen vapour as a risk factor in pathogen transfer. Theriogenology 71:1079-1082.

Kim, I. H.; Son, D. S.; Lee, H. J.; Yang, B. C.; Lee, D. W.; Suh, G. H.; Lee, K. W. and Jung, S. C. 1998. Bacteria in semen used for IVF affect embryo viability but can be removed by stripping cumulus cells by vortexing. Theriogenology 50:293-300.

Koneman, E. W.; Allen, S. D.; Janda, W. M.; Schreckenberger, P. C. and Winn Jr, W. C. 2001. Diagnóstico microbiológico: texto e atlas colorido. 5.ed. Guanabara Koogan, Rio de Janeiro. 
McDonnel, G. and Russell, D. 1999. Antiseptics and disinfectants: activity, action, and resistance. Clinical Microbiology Reviews 12:147-179.

Morris, G. J. 2005. The origin, ultra structure, and microbiology of the sediment accumulating in liquid nitrogen storage vessels. Cryobiology 50:231-238.

Neufeld, P. M. 1999. Manual de micologia médica: técnicas básicas de diagnóstico. PNCQ, Rio de Janeiro.

Papis, K. 2001. "Open" vitrification methods and their application in mammalian oocyte and embryo cryopreservation. Medycyna Weterynaryjna 57:547-551.

Piasecka-Serafin, M. 1972. The effect of the sediment accumulation in containers under experimental conditions on the infection of semen stored directly in liquid nitrogen $\left(-196^{\circ} \mathrm{C}\right)$. Bulletin de 1"Academie Polonaise des Sciences. Serie des Sciences Biologiques 20:263-267.

Russell, P. H.; Lyaruu, V. H; Millar, J. D.; Curry, M. R. and Watson, P. F. 1995. The potential transmission of infectious agents by semen packaging during storage for artificial insemination. Animal Reproduction Science 47:337-342.

Thibier, M. and Guerin, B. 2000. Hygienic aspects of storage and use of semen for artificial insemination. Animal Reproduction Science 62:233-251.

Zhu, G. J.; Wei, Y. L.; Hu, J. and Liu, Q. 2004. Microorganism contamination in vitro fertilization-embryo transfer system and their sources. Zhonghua fu chan ke za zhi 39:382-384. 